\title{
Adverse and Protective Influences of Adenosine on the Newborn and Embryo: Implications for Preterm White Matter Injury and Embryo Protection
}

\author{
SCOTT A. RIVKEES AND CHRISTOPHER C. WENDLER \\ Department of Pediatrics, Yale Child Health Research Center, Yale University School of Medicine, New Haven, Connecticut 06520
}

\begin{abstract}
Few signaling molecules have the potential to influence the developing mammal as the nucleoside adenosine. Adenosine levels increase rapidly with tissue hypoxia and inflammation. Adenosine antagonists include the methylxanthines caffeine and theophylline. The receptors that transduce adenosine action are the A1, A2a, $\mathrm{A} 2 \mathrm{~b}$, and $\mathrm{A} 3$ adenosine receptors (ARs). In the postnatal period, A1AR activation may contribute to white matter injury in the preterm infant by altering oligodendrocyte (OL) development. In models of perinatal brain injury, caffeine is neuroprotective against periventricular white matter injury (PWMI) and hypoxic-ischemic encephalopathy (HIE). Supporting the notion that blockade of adenosine action is of benefit in the premature infant, caffeine reduces the incidence of bronchopulmonary dysplasia and CP in clinical studies. In comparison with the adverse effects on the postnatal brain, adenosine acts via A1ARs to play an essential role in protecting the embryo from hypoxia. Embryo protective effects are blocked by caffeine, and caffeine intake during early pregnancy increases the risk of miscarriage and fetal growth retardation. Adenosine and adenosine antagonists play important modulatory roles during mammalian development. The protective and deleterious effects of adenosine depend on the time of exposure and target sites of action. (Pediatr Res 69: 271-278, 2011)
\end{abstract}

\section{Adenosine Physiology}

Adenosine. Adenosine consists of an adenine group attached to a ribose moiety. Adenosine is present in all cells and is a component of nucleic acids and energy-carrying molecules $(1,2)$. Adenosine can be directly released from the cell or generated extracellularly (3).

Within the cell, adenosine is produced from the hydrolysis of $S$-adenylyl homocysteine, ATP, ADP, or cAMP (Fig. 1) (4). Carrier-mediated processes transport intracellular adenosine to the extracellular space via bidirectional transporters $(1,5)$. Intracellular adenosine disposal involves adenosine kinase (AK) that converts adenosine to AMP (6). Adenosine is also converted to inosine by adenosine deaminase (ADA) (7).

Received September 21, 2010; accepted November 10, 2010.

Correspondence: Scott A. Rivkees, M.D., Department of Pediatrics, Yale Child Health Research Center, 464 Congress Avenue; Room 237, New Haven, CT 06520; e-mail: scott.rivkees@yale.edu

Supported by NIH Grants 1R01HD056281, 1R01NS068039, and R21NS051191.
Extracellular ATP is an important source of adenosine after the conversion of ATP to ADP and AMP. Enzymes that catalyze these reactions include the ectonucleotidases CD28 and CD39 that convert ATP to ADP and AMP, and P73 that converts AMP to adenosine (4). Little is known about the developmental expression and regulation of these enzymes. Contributing to elevations of adenosine levels during hypoxia, there is increased CD39 and CD73 activity, reduced cellular uptake of adenosine, and reduced AK activity in hypoxic conditions $(6,8)$.

Under basal conditions, interstitial adenosine levels are $1-50 \mathrm{nM}(2,6)$. Adenosine levels rapidly increased to $>1 \mu \mathrm{M}$ with tissue ischemia, hypoxia, and inflammation (2). Local adenosine levels thus provide a barometer of tissue activity and oxygenation with tissue oxygenation acting to decrease adenosine levels and oxygen deprivation increasing adenosine concentrations.

Adenosine receptors. There are two major classes of purine receptors-P1 and P2 $(9,10)$. ATP and ADP bind to P2 purine receptors that include $\mathrm{P} 2 \mathrm{Y}$ purine metabotropic receptors that couple with $\mathrm{G}$-proteins (10). $\mathrm{P} 2$ receptors also include the $\mathrm{P} 2 \mathrm{X}$ receptors that are ion channels (10).

Adenosine receptors (ARs) are $\mathrm{P} 1$ purine receptors $(9,11,12)$. A1 and A3ARs inhibit adenylyl cyclase, and A2a and A2bARs stimulate adenylyl cyclase $(9,11,12)$. Similar to other G-protein-coupled receptors (GPCRs), ARs contain seven putative transmembrane (TM) spanning domains $(9,11,12)$. ARs were initially cloned as orphan receptors (13). The identities of the genes encoding the A2a, A1, A2b, and A3 ARs were subsequently established in sequential order (14-19).

Each AR subtype has a different pattern of tissue expression and ligand-binding properties. In cell-based systems, A1ARs have the highest affinity for adenosine $\left(K_{i} 10 \mathrm{nM}\right)(9,11,12)$. The $K_{i}$ values for adenosine for the A2a, A2b, and A3 ARs are 200, 2,000, and 10,000 $\mathrm{nM}$, respectively, for the human

Abbreviations: AR, adenosine receptor; E, embryonic day; HIE, hypoxic ischemic encephalopathy; OL, oligodendrocyte; PreOL, preoligodendrocyte; PVL, periventricular leukomalacia; PWMI, periventricular white matter injury 


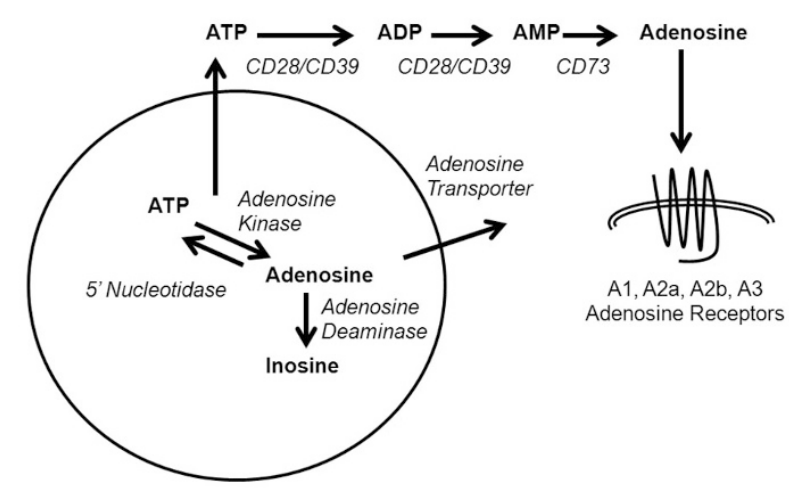

Figure 1. Adenosine action. Adenosine is generated at intra- and extracellular sites from the breakdown of ATP. Extracellular adenosine binds to G-protein-coupled P1 purine receptors, A1, A2a, A2b, and A3. A1 and A3 receptors are $\mathrm{Gi} / \mathrm{o}-$ coupled. $\mathrm{A} 2 \mathrm{a}$ and $\mathrm{A} 2 \mathrm{~b}$ receptors are Gs-coupled and increase intracellular cAMP levels.

receptors $(9,11,12)$. A3ARs are also activated by the adenosine metabolite inosine $\left(K_{i} 2300 \mathrm{nM}\right)(9,11,12)$.

In hypoxia and inflammation, A2a and A2bAR expression is induced, in part, via hypoxia-inducible factor (HIF) action (20). As such, in addition to increasing adenosine production, there is amplification of cellular adenosine target expression with hypoxia or inflammation.

During development, A1ARs play an important role in transducing adenosine physiological effects. A1ARs are 326 amino acids in length with seven TM-spanning domains (18). A1ARs activate $\mathrm{Gi}$ and Go, inhibit cAMP accumulation, activate phospholipase $\mathrm{C}$, and open ion channels (11).

Theoretical models of ligand-A1AR interaction have been developed based on site-directed mutagenesis studies (21). A1ARs, although, have not been crystallized, like A2ARs (22), to confirm the proposed ligand-receptor interaction models.

A1AR-selective compounds are available and include the agonist $N^{6}$-cyclopentyladenosine (CPA) (23). Specific A1AR antagonists include 8-cyclopentyl-1,3-dipropylxanthine (DPCPX) (23). Methylxanthines, including caffeine and aminophylline, are nonselective adenosine antagonists that block A1ARs and other ARs (23).

AR expression in mature mammals. Highest levels of $A l A R$ gene expression are detected in adult brain, fat, and testis (18). Less prominent A1AR expression is seen in the heart and kidneys (18). A2aAR gene expression is seen in brain, heart, and lung (17). A2bAR mRNA expression is highest in colon and bladder (24). A2bARs expression is also high in retina (25). A3AR gene expression is found in testis, heart, and retina (19). Although levels of gene and binding site expression are proportional for A1 and A2aARs, gene expression is much greater than binding site expression for A3ARs (26).

In the brain, A2aARs are expressed in several brain regions, and heavy expression is seen in the striatum on cells expressing D2 dopamine receptors, an observation that dates back 2 decades (17). A2bAR expression is localized to the pars tuberalis region of the hypophysis $(16,24)$. Functional studies have suggested the presence of A3ARs in the CNS (27).

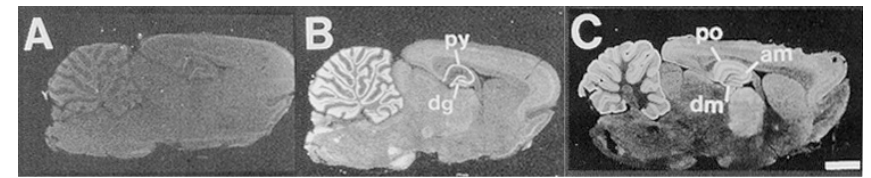

Figure 2. A1AR mRNA and binding site expression in rat brain. Sense $(A)$ and antisense $(B)$ images generated from in situ hybridization studies are shown. (C) Specific $\left[{ }^{3} \mathrm{H}\right]$ DPCPX labeling by receptor autoradiography. Specific labeling appears as white. Note the mismatch between patterns of mRNA and receptor labeling. The mRNA is expressed over cells in the granular layer of the dentate gyrus (dg) and over cells in the pyramidal layer (py) of Ammon's horn. In contrast, $\left[{ }^{3} \mathrm{H}\right] \mathrm{DPCPX}$ labeling of A1ARs is greatest in the dentate gyrus molecular layer (dm), the polymorphic (po), and molecular layers (am). Scale bar $=25 \mathrm{~mm}$. Reprinted from Swanson TH et al. J Comp Neurol 363:517-531; Copyright @ 1995 Wiley-Liss, Inc., with permission.

A1ARs are among the most widespread GPCRs in the brain (Fig. 2). In comparison with the relatively discrete expression of other receptor subtypes, A1AR expression is at high level throughout the brain $(18,28)$. A1ARs are detected on neuronal cell bodies, oligodendrocytes (OLs), and axons, with A1AR immunoreactivity heavy on white matter tracks (28). A1ARs are also present on nerve terminals (29), where they can act to regulate growth cone structure (30) and influence neurotransmitter release (31).

In the heart, A1AR expression is present in atria and ventricles, and atrial A1AR expression is greater than that seen in the ventricles (32). A2aARs are present in coronary vessels in endothelial cells, smooth muscle cells of blood vessels, and on myocytes (33). A3ARs are present in myocardial tissue, although at low levels (19). A2bARs are present on endothelial cells, smooth muscles cells, and fibroblasts (34).

In several tissues, A2aARs are present on endothelial and smooth muscle cells of the vasculature and induce vasodilation and reduced endothelial integrity (35). A2aARs play an immunosuppressive role by acting on invariant natural killer-T cells and neutrophils $(36,37)$. A2bARs are expressed on fibroblasts, mesenchymal cells, and macrophages and act to influence tissue injury repair (38). A2bARs have been reported to be present on $\mathrm{T}$ cells and neutrophils, and their activation dampens the immune response (39). Recently, A2bARs have been identified on type II pneumocytes in the lung (38). A3ARs are expressed in mast cells and influence histamine release (40). ARs are thus localized at sites to modulate nervous system, cardiovascular system, and pulmonary and immune system function.

Developmental expression of A1ARs. Although it is likely that several of the different AR subtypes play important and possibly protective roles during development, we know more about the role of A1ARs in this regard, which is the major focus of this report. A1AR expression is present in the brain when neural tissue first appears, and A1ARs are one of the earliest expressed GPCRs in the fetal heart (32).

During early embryogenesis, when the primitive cardiac cylinder appears, AlAR gene expression is seen over the developing myocardium. Labeling of the nodal region, which controls embryo situs, is also seen (32). Later in embryogenesis, A1AR expression is seen in the heart, brain, spinal cord, and kidney (32). Within the heart, A1AR binding site expression is more prominent over the atria than the ventricles (32). 
Reporter assay studies reveal that 500 base pairs of the proximal A1AR promoter contains essential elements for AlAR gene expression (41). Within the proximal A1AR promoter, putative binding sites for cardiac transcription factors GATA4 and Nkx2.5 were identified (41). Embryonic A1AR expression thus involves activation of the A1AR promoter by GATA-4 and Nkx2.5.

A1ARs are expressed in the nervous system during periods of neuronal birth, migration, and axon sprouting (32). A1AReffector coupling has been observed in embryonic neurons and in the fetal and neonatal brain (42). A1AR activation can induce growth cone collapse in growing neurons (30). These observations show that there is early functional A1AR effector system coupling, an issue that had been questioned (43).

\section{Adenosine and Periventricular White Matter Injury}

Origins of the adenosine and perinatal brain injury hypothesis. In the preterm infant, caffeine is well recognized to stimulate respiration and is widely used clinically (44). In the adult brain, A1AR activation exerts protective effects against ischemic and excitotoxic injury, which is blocked by caffeine (45). Although caffeine blocks acute neuroprotective effects of adenosine, chronic caffeine consumption has been observed to exert protective neurological effects in adults $(45,46)$. During development, caffeine was viewed to have potentially adverse rather than protective effects on the developing nervous system (44). Thus, the notion that adenosine could contribute to neonatal brain injury and that adenosine blockade was protective was not a prevailing view. A series of animal studies, although, revealed that these assumptions did not apply during development.

The selective deletion of A1ARs in mice was not associated with overt brain structural abnormalities, whereas mild behavioral effects were observed (47). Considering that adenosine exerts effects in situations of increased production, effects of sustained A1AR activation on brain development were examined (42). Surprisingly, when neonatal rats were treated with A1AR agonists, marked reductions in white and gray matter volume were observed along with secondary ventriculomegaly (42), similar to that seen in hypoxia-reared rodents (Fig. 3). Quantitative electron microscopy revealed reduction in total axon volume, and reduced expression of myelin basic protein (MBP) was seen. It is possible that the effects of A1AR agonist treatment reflects effects of sustained A1AR activation. Alternatively, it is possible that sustained activation of A1ARs leads to receptor desensitization and altered A1AR action (48).

Genetically-engineered mice deficient in ADA with circulating levels of adenosine 100-fold higher than control animals (49) were also found to have ventriculomegaly and reduced myelination (50). Importantly, the neuroanatomy of A1AR agonist-treated and the ADA-deficient pups was strikingly similar to that of the clinical condition periventricular white matter injury [PWMI; also referred to as diffuse periventricular leukomalacia (PVL)], a condition affecting preterm infants associated with hypomyelination (51).
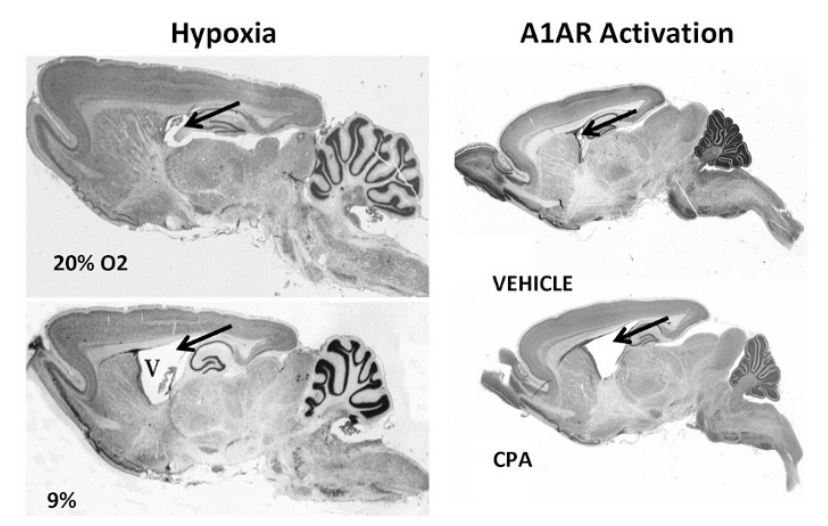

Figure 3. A1AR activation induces PWMI. Left panel: neonatal rats reared in hypoxia manifest features of PWMI including white matter loss and secondary ventriculomegaly (V). Reprinted from Ment LR et al. Brain Res Dev Brain Res 111:197-203; Copyright (C) 1998 Elsevier Science B.V., with permission. Right panel: neonatal rats treated with the A1AR agonist, $N^{6}$ cyclopentyladenosine manifest features of PWMI similar to that observed in hypoxia. Arrows depict location of ventricles.

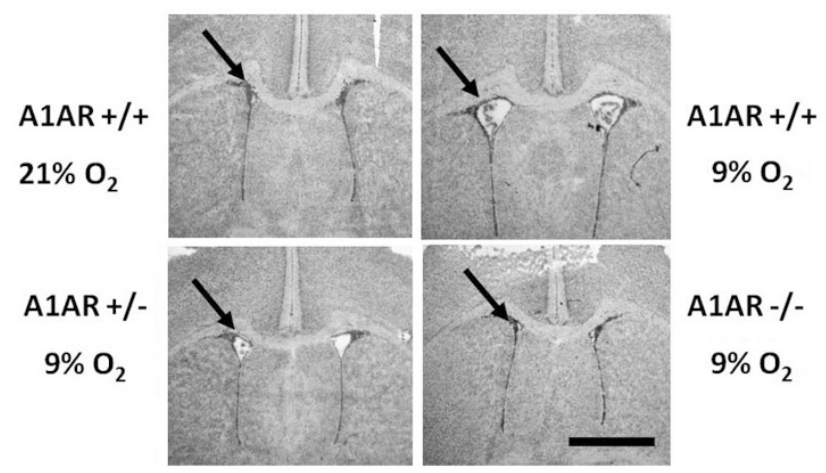

Figure 4. Deletion of A1ARs protects against PWMI. Hematoxylin-stained coronal sections from $\mathrm{A} 1 \mathrm{AR}+/+, \pm$, or $-/-$ animals taken from the midstriatum of P14 mice exposed from P3 through P14 to either chronic sublethal hypoxia $\left(9.5 \% \mathrm{O}_{2}\right)$ or room air. Ventricular enlargement was observed in $+/+$ and \pm mice exposed to hypoxia but not in $-/-$ mice exposed to hypoxia and $+/+$ mice reared in normoxia. Scale bar: $1 \mathrm{~mm}$. Reprinted from Turner CP et al. Proc Natl Acad Sci U S A 100:11718-11722; Copyright (C) 2003 The National Academy of Sciences of the U.S.A., with permission.

Because it was observed that rearing neonatal mice in hypoxia induced a PWMI phenotype with reduced myelination and ventriculomegaly (52), mice lacking A1ARs (A1AR-/-) were studied in hypoxia. Although marked ventriculomegaly was observed in the hypoxia-exposed newborns, PWMI was prevented in the mice lacking A1ARs (Fig. 4) (50). These observations showed that rather than exerting protective effects, adenosine acts via A1ARs to induce diffuse white matter injury in the developing brain and may play a role in PWMI causation.

Influences of adenosine on OLs. PWMI reflects injury to or altered maturation of OLs, which are the myelinating cells of the brain (51). OL development involves progression through four recognized stages of development: OL precursor cells (OPC), preoligodendrocyte (PreOLs), immature OLs, and mature OLs. Damage to or altered development of PreOLs 
is believed to be a major factor in PWMI causation (51); PreOLs are the predominant OL stage present when the risk for PWMI is greatest (51).

An important feature of OLs is that they express each of the different AR subtypes (53). Interestingly, treatment of OPCs in culture with adenosine promotes accelerated OL maturation, an effect that is A1AR mediated (54). Activation of A1ARs also stimulated OPC migration, without adverse affects on cell viability (53).

Similarly, studies of OPCs and PreOLs in hypoxia reveal accelerated maturation and reduced proliferation (55). Increased expression of the cell cycle regulatory proteins p27(Kip1) and phospho-cdc2 are seen, showing that hypoxia induces premature OPC maturation (55).

These data show that hypoxia-induced hypomyelination is associated with altered OL lineage progression and that adenosine plays a prominent role in this process. Rather than causing OL death, adenosine and hypoxia lead to premature differentiation of OPCs. It is postulated that this series of events leads to reduced numbers of OLs contributing to PWMI. As such, strategies aimed at stimulating OL proliferation may provide a basis for developing new PWMI treatments (56).

Protective influences of caffeine on the PWMI. Caffeine is a nonselective adenosine antagonist (45) widely used in neonatal medicine to stimulate respiration in premature infants (57). The $\mathrm{IC}_{50}$ value at which caffeine binds to $\mathrm{A} 1$ and A2aARs is $\sim 10 \mu \mathrm{M}$ (45), with complete receptor saturation observed $\sim 100 \mu \mathrm{M}$ (45).

To test whether caffeine has neuroprotective effects, neonatal mice reared in hypoxia were treated with caffeine (58). We observed that ventriculomegaly and hypomyelination was reduced by caffeine treatment (58) (Fig. 5). Caffeine treatment resulted in more normally arranged myelinated axon orientation than that observed in hypoxia (58). Caffeine also increased the proportion of immature OLs (58). Providing further support for the notion that caffeine is neuroprotective in

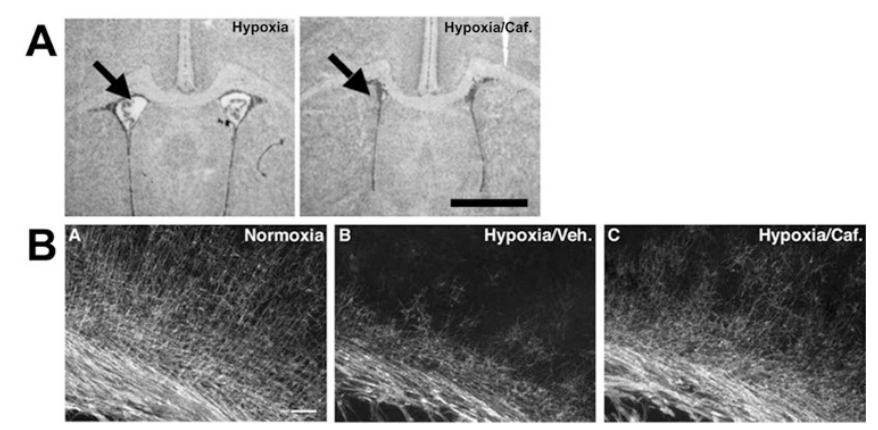

Figure 5. Caffeine protects against PWMI. (A) Representative coronal views of the lateral ventricles (arrow) for mice reared in hypoxia by dams drinking water (upper panel) or water-containing caffeine (CAF; lower panel). Ventriculomegaly was not seen in mice reared in hypoxia by dams drinking water with caffeine. $(B)$ Caffeine treatment during chronic sublethal hypoxia ameliorates reductions in cerebral myelination. MBP staining shows the typical myelination patterns of animals reared in normoxia $(A)$ relative to those in chronic hypoxia treated with vehicle $(\mathrm{Veh} ; B)$ or with caffeine $(\mathrm{Caf} ; C)$. Scale bar: 1 mm. Reprinted from Back SA Ann Neurol 60:696-705; Copyright (C) 2006 American Neurological Association, with permission. development, improved myelination was seen in nonrandomized studies of premature baboons treated with caffeine (59).

Recently, clinical studies support the notion that caffeine has beneficial effects in the premature infant $(57,60,61)$. Preterm infants randomized to be treated with caffeine or placebo in the caffeine for apnea of prematurity (CAP) study had reduced rates of bronchopulmonary dysplasia (BPD) and patent ductus arterious (PDA) when treated with caffeine $(57,60,61)$. Caffeine-treated infants had significantly lower rates of $\mathrm{CP}$ than the control group $(57,60,61)$. This effect was most prominent in infants with respiratory distress (61). Brain imaging data, although, are needed to directly assess influences on white matter formation.

It is also important to note that the onset of caffeine therapy was on average at 3 days of age in the CAP study, and it is likely that adverse effects of adenosine on OLs have taken place by this age. Studies of earlier intervention caffeine use, coupled with direct assessment of white matter structure by contemporary imaging methods, are indicated to determine whether caffeine is indeed neuroprotective in the premature infant, before caffeine therapy is adopted for neuroprotective purposes.

Other neuroprotective roles of caffeine. Although we postulate that caffeine exerts neuroprotective effects by blocking adenosine action on OLs, it is likely that caffeine involves action at other ARs. A2a and A2bARs are located on capillaries and their activation can induce capillary leak (35), raising the possibility that adenosine contributes to intraventricular hemorrhage (IVH). Because IVH occurs shortly after birth, potential preventative effects of caffeine on IVH may only be detected with early intervention. Interestingly, CAP data show lower IVH rates in the caffeine-treated infants than the placebo group (60). It is indeed likely that these actions reflect effects of caffeine on blood-brain barrier function of the infant.

Another cause of perinatal brain injury is hypoxic-ischemic encephalopathy (HIE), which affects preterm and term infants (62). Although the chronic sublethal hypoxia model best mimics diffuse PWMI (52), the ischemic-reperfusion model better recapitulates HIE and stroke injury (63).

Studies performed $>1$ decade ago revealed that caffeine reduced brain injury in mice after HIE (64). To date, studies of transgenic mice have not revealed that a single AR mediates caffeine-protective effects, as protective effects of caffeine are seen in A1, A2a, A2b, and A3 knockout mice (65). Protective caffeine effects on HIE are thus either AR independent or two or more receptor subtypes mediate this form of brain injury.

It is also important to consider that although protective effects of adenosine antagonism have been observed, as noted above, other investigators have observed adverse effects $(44,66,67)$. These differences are likely related to the timing of the insults, which are in more mature animals.

\section{Adenosine Influences on Respiratory Funciton}

Adenosinergic influences on respiration and lung disease. For several decades, caffeine has been observed to promote respiratory drive in term and premature infants providing a 

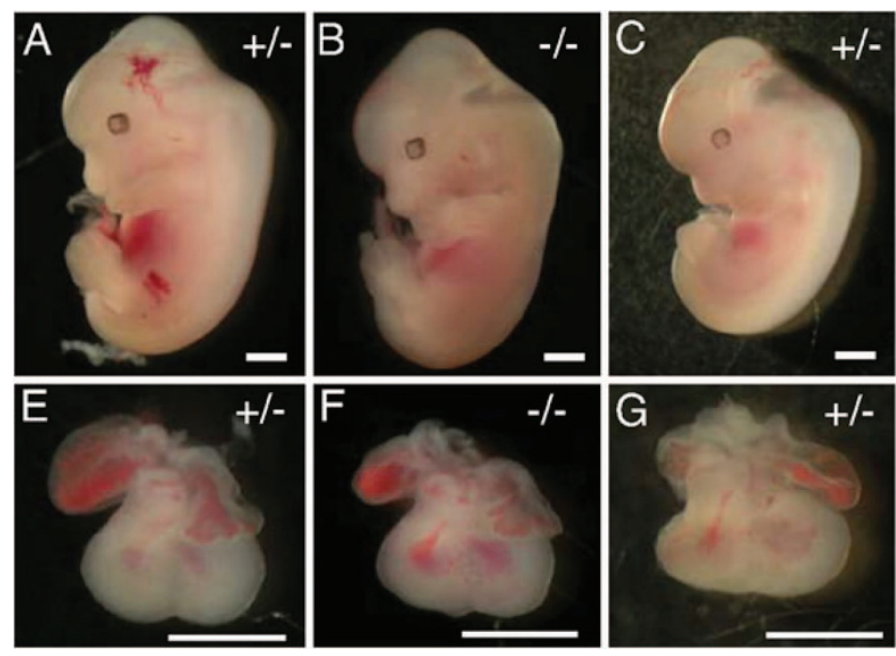

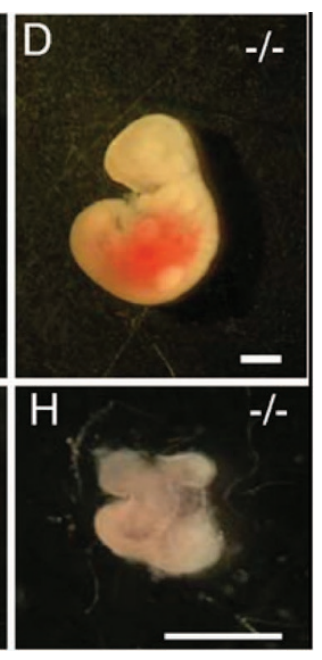

Figure 6. A1ARs protect against growth retardation in embryos. Hypoxia induces severe growth retardation in A1AR-/- embryos. Dams were exposed to $10 \% \mathrm{O}_{2}$ from E8.5 to E12.5. C-R length was measured for normoxia and hypoxiatreated embryos at E12.5. Under normoxia conditions, (A) $\mathrm{A} 1 \mathrm{AR} \pm$ embryos were indistinguishable from A1AR-/- $(B)$ embryos. Under hypoxic conditions, $\mathrm{A} 1 \mathrm{AR} \pm$ embryos $(C)$ were smaller then the normoxic controls $(A)$, but A1AR-/- embryos $(D)$ were significantly smaller than $\mathrm{A} 1 \mathrm{AR}-/-$ or $\mathrm{A} 1 \mathrm{AR} \pm$ normoxic embryos. A1AR $-/-$ hypoxic hearts $(H)$ were smaller than $\mathrm{A} 1 \mathrm{AR} \pm$ normoxic $(E), \mathrm{A} 1 \mathrm{AR}-/-$ normoxic $(F)$, or A1AR \pm hypoxic hearts $(G)$. Scale bars: $1 \mathrm{~mm}$. Reprinted from Wendler CC et al. Proc Natl Acad Sci U S A 104:9697-9702; Copyright (C) 2007 The National Academy of Sciences of the U.S.A., with permission. basis for use in treating apnea (44). Studies of transgenic mice indicate that adenosine exerts suppressive effects on respiration via A1ARs (47). Stimulatory effects of caffeine on respiration are not observed in A1AR knock-out mice, identifying A1ARs as mediating caffeine-stimulated respiratory drive (47).

An important beneficial effect of caffeine observed in the CAP study was a reduction in rates of $\operatorname{BPD}(57,60,61)$. At present, the biological basis of this observation is not known. However, it is likely that this effect reflects blockade of A2aARs and/or A2bARs, which influence capillary permeability, inflammation, and lung remodeling as these receptor subtypes promote capillary leak $(8,34)$.

A2aARS can act on immune cells to modulate inflammation, generally having anti-inflammatory actions, but varying with cell type effected $(37,68)$. Activation of A2aARs on neutrophils can result in neutrophil infiltration $(37,68)$. A2bARs activation can contribute to inflammation in the lung, as A2bARs on macrophages trigger cytokine release that contributes to pulmonary fibrosis (69). Although it is clear that adenosine plays an important role in developmental lung injury, further studies of adenosine action on vascular leak, inflammation, and fibrosis are needed to elucidate the mechanisms involved in developmental lung injury.

\section{Adenosine Influences on the Embryo}

Influences on embryogenesis. Because adenosine and A1ARs mediate adverse effects of hypoxia on the developing postnatal brain and lung (50), we anticipated that blockade of adenosine action would protect embryos from hypoxia (50). To our surprise, we observed that adenosine exerts dramatic protective effects during embryogenesis $(70,71)$.

Timed pregnant dams from $\mathrm{A} 1 \mathrm{AR} \pm \times \mathrm{A} 1 \mathrm{AR}-/-$ matings were exposed to hypoxia or room air during early embryogenesis (71). Under normoxic conditions, embryos lacking A1ARs develop normally. However, embryos lacking A1ARs were markedly growth retarded in hypoxia (71) (Fig. 6). These data show that adenosine acting via A1ARs play an important role in protecting the embryo from hypoxia.
Observing A1AR embryo protective roles, the molecular pathways that may mediate these effects were examined. We found differences in networks of molecular responses to hypoxia, suggesting that adenosine alters HIF1- $\alpha$ signaling (71). We also found that the amount of stabilized HIF- $1 \alpha$ protein was markedly reduced in A1AR-/- embryos exposed to hypoxia (71).

After embryonic day (E) 10 in mice, the embryo is dependent on the fetal heart for adequate nutrient delivery (6). Thus, to test whether adenosine confers embryo protective effects by acting at the heart, mice that lack A1ARs only in the heart were developed (70). Remarkably, we observed that embryos lacking cardiac A1ARs had reduced survival in hypoxia, and those that survived were growth retarded (Fig. 7).

These observations show that adenosine plays a key role in protecting the embryo against intrauterine stress, and adenosine exerts protective effects through A1ARs expressed in the heart. It is likely that adenosine action on embryo cardiac function plays a major role in embryonic responses to intrauterine stress.

Effects of caffeine on the embryo. Because caffeine is widely consumed, potential effects of caffeine on the developing fetus have been examined in animals and humans (72). A cup of coffee, tea, or cola contains 100-300 mg of caffeine, and it is estimated that $>60 \%$ of pregnant women consume caffeine-containing beverages (72). After administration to pregnant rodents, embryo and fetal caffeine levels are $90 \%$ of maternal levels $(45,72)$. Fetal caffeine clearance is much longer than that observed in the dam, with a half-life of 12-24 h $(45,72)$.

In rats, teratogenic effects of caffeine on the fetal heart are observed at doses in excess of $50 \mathrm{mg} / \mathrm{kg}$ (73). The most common cardiovascular malformations are ventricular defects (74). Cardiac morphogenesis has been found to be impaired in embryos from mothers treated with both ethanol and caffeine (75), showing that caffeine can amplify effects of other toxins.

In contrast to animal studies, major teratogenic effects of caffeine have not been found in humans (73). Few studies, although, have evaluated effects of caffeine consumption dur- 


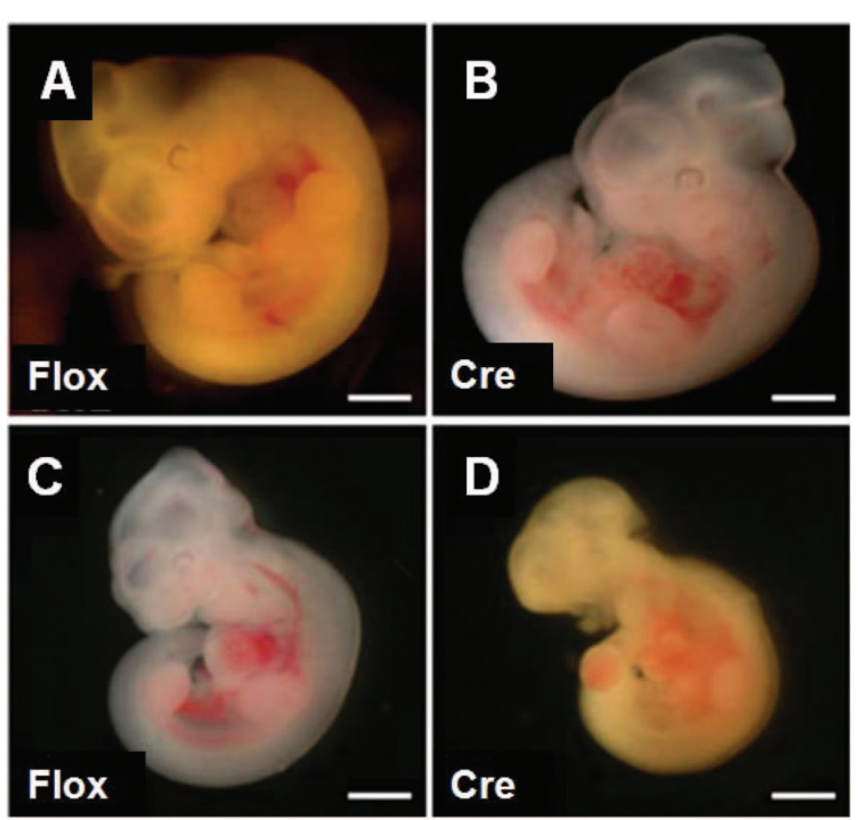

Figure 7. Cardiac A1ARs protect against hypoxia. Embryos exposed to hypoxia for 2 days in utero from E8.5 to 10.5 were not growth retarded compared with room air controls, but embryos exposed to hypoxia in utero from E10 to 12.5 exhibited significant growth retardation. Embryos exposed to hypoxia for $3 \mathrm{~d}$ demonstrated an even greater amount of growth retardation compared with controls. Normoxic embryos both $(A)$ normox/flox and $(B)$ normox/Cre displayed normal morphology and growth. The hypoxic embryos $(C)$ hypox/flox and $(D)$ hypox/cre were significantly growth retarded; however, there was no difference between hypox/Flox and hypox/Cre embryos. Scale bar is $1 \mathrm{~mm}$. Reprinted with authors' permission from Wendler CC et al. BMC Dev Biol 10:57; Copyright () 2010 Wendler et al.

ing early embryogenesis (72,73). Recent studies reveal that coffee consumption is associated with an increased risk of cardiovascular malformations $(72,76)$. Caffeine consumption during pregnancy is also associated with an increased risk of miscarriage in a dose-dependent manner, an effect most pronounced in early pregnancy $(77,78)$.

Clinical studies suggest that caffeine may influence fetal growth. The risk of having small for GA infants is doubled if mothers have high caffeine intake (79). Women who reduce their caffeine intake from $>300 \mathrm{mg} / \mathrm{d}$ to less than that amount early in pregnancy have lower risks of delivering infants with LBW than women who do not $(79,80)$.

Considering the above, we tested whether caffeine exerts effects on the embryo similar to that seen when A1ARs are deleted (81). Pregnant mice in room air or hypoxia were treated with a single dose of caffeine at E8.5 resulting in circulating concentrations in the dam equivalent to those seen with two cups of coffee (45). The time of exposure was equivalent to 20-30 d of human gestation, a time when many women are not aware that they are pregnant.

Caffeine was associated with reduced fetal viability (81). When embryo size was assessed, the caffeine-treated embryos were smaller than vehicle-treated embryos (Fig. 8) (81). When cardiac histology was examined, caffeine resulted in reduced ventricular myocardial area (Fig. 8). Caffeine also reduced HIF-1 $\alpha$ protein expression in hypoxia (81) (Fig. 9).

We next assessed whether there were long-term effects of prenatal caffeine exposure. Pregnant dams were exposed to

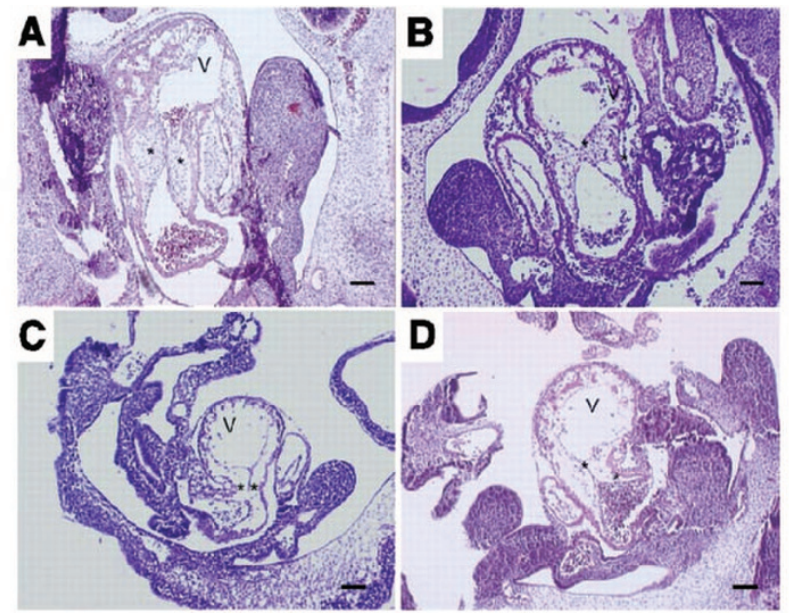

Figure 8. Hypoxia and caffeine treatment lead to reduced ventricular myocardial tissue. Embryos were exposed to hypoxia and caffeine from E8.5 to E10.5. Compared with NorNS $(A)$, ventricular myocardial area was decreased by $37.3 \%$ in the $\operatorname{NorCf}(B)$ group. Exposure to hypoxia caused a more substantial decrease in myocardial area, including $55.7 \%$ in the HyNS group $(C)$ and $53.3 \%$ in the HyCf group (D5). V, ventricle; *, endocardial cushion. Scale bars $=100 \mu \mathrm{m}$. Reprinted from Wendler CC et al. FASEB J 23:12721278; Copyright $\odot 2009$ FASEB, with permission.

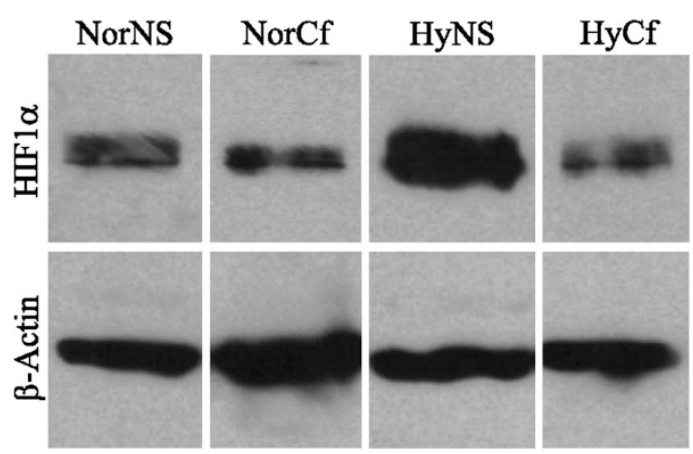

Figure 9. Caffeine blocks hypoxia-induced $\mathrm{HIF} 1 \alpha$ protein accumulation in hypoxic embryos. Caffeine treatment inhibited HIF1 $\alpha$ protein accumulation in hypoxic embryos. Dams were injected with normal saline or $20 \mathrm{mg} / \mathrm{kg}$ caffeine and then placed immediately in hypoxia $\left(10 \% \mathrm{O}_{2}\right)$ or left in room air $\left(21 \% \mathrm{O}_{2}\right)$. Embryos were collected after $6 \mathrm{~h}$, and whole embryo protein was isolated. Western blot analysis of HIF1 $\alpha$ protein expression demonstrated a $40 \%$ reduction in stabilized HIF1 $\alpha$ protein in caffeine-treated embryos exposed to hypoxia. $\beta$ Actin protein was examined on the same Western blots as a loading control. Reprinted from Wendler CC et al. FASEB J 23:12721278; Copyright (C) 2009 FASEB, with permission.

hypoxia or room air from E8.5 to 10.5 and treated with caffeine or vehicle. At 2 mo of age, the hypoxia-caffeine exposed male mice were significantly heavier than controls, and body fat content was significantly greater when there was prenatal caffeine exposure (81). Echocardiography of adult animals revealed decreases in cardiac function in the groups exposed to the single dose of caffeine (81).

At present, the adenosine-mediated effects, which are disrupted by caffeine that trigger embryo loss or altered fetal development, are not known. During early embryogenesis, cardiac output is much dependent on fetal heart rate. We observe that caffeine leads to alterations in embryo heart rate. It has also been observed that caffeine alters maternal cardiac output and effects embryo cardiovascular function (82). Thus, 
it is likely that alteration in embryo cardiac activity by caffeine leads to altered tissue perfusion, contributing to embryo loss, or altered embryo development.

\section{Conclusion}

An expanding body of data show that adenosine plays an important role during pre- and postnatal development. Increased A1AR action at stages equivalent to the last trimester of pregnancy perturbs OL development resulting in hypomyelination and a PWMI phenotype. Caffeine treatment or deletion of A1ARs promotes myelination in neonates exposed to hypoxia. Thus, we have identified unique aspects of A1AR action that leads to PWMI (Fig. 10).

In contrast to the neonatal period, reduced A1AR action during embryogenesis leads to embryo loss, acute growth retardation, and hearts with thinner ventricular walls. Caffeine induces defects similar to that seen in embryos lacking A1ARs exposed to hypoxia. A1ARs are needed for full stabilization of HIF- $1 \alpha$ protein in hypoxia. Embryonic caffeine treatment is associated with increased body fat and reduced cardiac function in adulthood. Thus, we have identified unique aspects of A1AR action that protects the embryo against acute hypoxic insults at embryonic stages (Fig. 11). As such, it is possible that the mechanism by which caffeine leads to embryo loss during early gestation is via blockade of A1AR action.

Adenosine plays important modulatory roles in mammalian development, conferring protective or deleterious effects de-

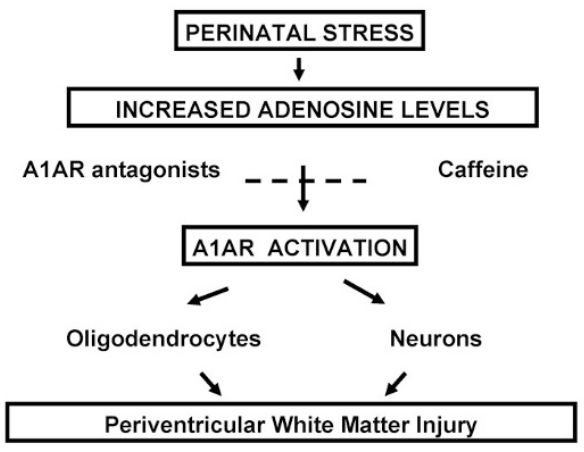

Figure 10. Cartoon depicting contribution of adenosine to PWMI.

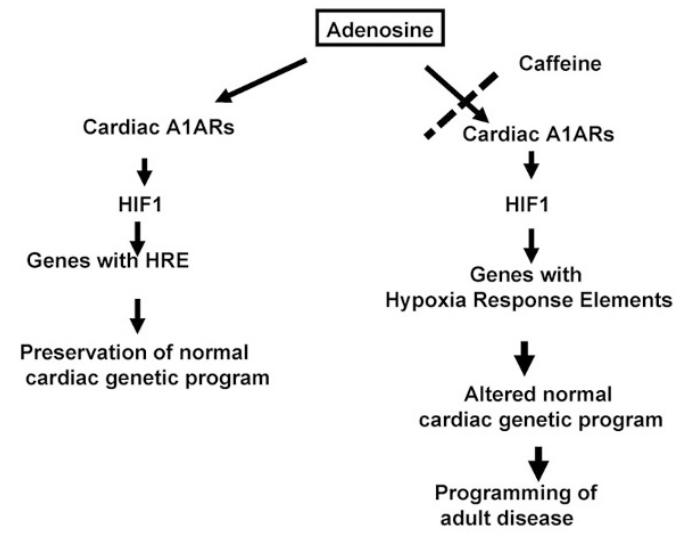

Figure 11. Cartoon depicting contribution of adenosine to protecting the embryo against intrauterine stress and how this is disrupted by caffeine. pending on the timing of exposure and site of action. As such, adenosine antagonists, including caffeine, may be an unwelcome exposure for the embryo but a welcome therapeutic for the preterm infant.

\section{REFERENCES}

1. Jacobson KA 2009 Introduction to adenosine receptors as therapeutic targets. Handb Exp Pharmacol 193:1-24

2. Rivkees SA, Zhao Z, Porter G, Turner C 2001 Influences of adenosine on the fetus and newborn. Mol Genet Metab 74:160-171

3. Eckle T, Koeppen M, Eltzschig HK 2009 Role of extracellular adenosine in acute lung injury. Physiology (Bethesda) 24:298-306

4. Eltzschig HK, Weissmuller T, Mager A, Eckle T 2006 Nucleotide metabolism and cell-cell interactions. Methods Mol Biol 341:73-87

5. Eltzschig HK, Abdulla P, Hoffman E, Hamilton KE, Daniels D, Schonfeld C, Loffler M, Reyes G, Duszenko M, Karhausen J, Robinson A, Westerman KA, Coe IR, Colgan SP 2005 HIF-1-dependent repression of equilibrative nucleoside transporter (ENT) in hypoxia. J Exp Med 202:1493-1505

6. Conway SJ, Kruzynska-Frejtag A, Kneer PL, Machnicki M, Koushik SV 2003 What cardiovascular defect does my prenatal mouse mutant have, and why? Genesis 35:1-21

7. Van Linden A, Eltzschig HK 2007 Role of pulmonary adenosine during hypoxia: extracellular generation, signaling and metabolism by surface adenosine deaminase/ CD26. Expert Opin Biol Ther 7:1437-1447

8. Thompson LF, Eltzschig HK, Ibla JC, Van De Wiele CJ, Resta R, Morote-Garcia JC, Colgan SP 2004 Crucial role for ecto-5'-nucleotidase (CD73) in vascular leakage during hypoxia. J Exp Med 200:1395-1405

9. Fredholm BB 2010 Adenosine receptors as drug targets. Exp Cell Res 316:12841288

10. Abbracchio MP, Burnstock G, Verkhratsky A, Zimmermann H 2009 Purinergic signalling in the nervous system: an overview. Trends Neurosci 32:19-29

11. Fredholm BB, IJzerman AP, Jacobson KA, Klotz KN, Linden J 2001 International Union of Pharmacology. XXV. Nomenclature and classification of adenosine receptors. Pharmacol Rev 53:527-552

12. Fredholm BB, Arslan G, Halldner L, Kull B, Schulte G, Wasserman W 2000 Structure and function of adenosine receptors and their genes. Naunyn Schmiedebergs Arch Pharmacol 362:364-374

13. Libert F, Parmentier M, Lefort A, Dinsart C, Van Sande J, Maenhaut C, Simons MJ, Dumont JE, Vassart G 1989 Selective amplification and cloning of four new members of the $G$ protein-coupled receptor family. Science 244:569-572

14. Maenhaut C, Van Sande J, Libert F, Abramowicz M, Parmentier M, Vanderhaegen JJ, Dumont JE, Vassart G, Schiffmann S 1990 RDC8 codes for an adenosine A2 receptor with physiological constitutive activity. Biochem Biophys Res Commun 173:1169-1178

15. Libert F, Schiffmann SN, Lefort A, Parmentier M, Gerard C, Dumont JE, Vanderhaeghen JJ, Vassart G 1991 The orphan receptor cDNA RDC7 encodes an A1 adenosine receptor. EMBO J 10:1677-1682

16. Rivkees SA, Reppert SM 1992 RFL9 encodes an A2b-adenosine receptor. Mol Endocrinol 6:1598-1604

17. Fink JS, Weaver DR, Rivkees SA, Peterfreund RA, Pollack AE, Adler EM, Reppert SM 1992 Molecular cloning of the rat A2 adenosine receptor: selective co- expression with D2 dopamine receptors in rat striatum. Brain Res Mol Brain Res 14:186195

18. Reppert SM, Weaver DR, Stehle JH, Rivkees SA 1991 Molecular cloning and characterization of a rat A1-adenosine receptor that is widely expressed in brain and spinal cord. Mol Endocrinol 5:1037-1048

19. Zhou QY, Li C, Olah ME, Johnson RA, Stiles GL, Civelli O 1992 Molecular cloning and characterization of an adenosine receptor: the A3 adenosine receptor. Proc Natl Acad Sci U S A 89:7432-7436

20. Aherne CM, Kewley EM, Eltzschig HK 2010 The resurgence of A2B adenosine receptor signaling. Biochim Biophys Acta In press

21. Barbhaiya H, McClain R, Ijzerman A, Rivkees SA 1996 Site-directed mutagenesis of the human A1 adenosine receptor: influences of acidic and hydroxy residues in the first four transmembrane domains on ligand binding. Mol Pharmacol 50:1635-1642

22. Jaakola VP, Griffith MT, Hanson MA, Cherezov V, Chien EY, Lane JR, Ijzerman AP, Stevens RC 2008 The 2.6 angstrom crystal structure of a human A2A adenosine receptor bound to an antagonist. Science 322:1211-1217

23. Trivedi BH, Bridges AJ, Bruns RF 1990 Structure-activity relationships of adenosine $\mathrm{A} 1$ and A2 receptors. In: Williams M (ed) Adenosine and Adenosine Receptors. Humana Press, Clifton, pp 57-106

24. Stehle JH, Rivkees SA, Lee JJ, Weaver DR, Deeds JD, Reppert SM 1992 Molecular cloning and expression of the cDNA for a novel A2- adenosine receptor subtype. Mol Endocrinol 6:384-393

25. Blazynski C 1993 Characterization of adenosine A2 receptors in bovine retinal pigment epithelial membranes. Exp Eye Res 56:595-599

26. Rivkees SA, Thevananther S, Hao H 2000 Are A3 adenosine receptors expressed in the brain? Neuroreport 11:1025-1030

27. Lopes LV, Rebola N, Pinheiro PC, Richardson PJ, Oliveira CR, Cunha RA 2003 Adenosine A3 receptors are located in neurons of the rat hippocampus. Neuroreport 14:1645-1648

28. Swanson TH, Drazba JA, Rivkees SA 1995 Adenosine A1 receptors are located predominantly on axons in the rat hippocampal formation. J Comp Neurol 363:517531 
29. Rebola N, Coelho JE, Costenla AR, Lopes LV, Parada A, Oliveira CR, Soares-daSilva P, de Mendonca A, Cunha RA 2003 Decrease of adenosine A1 receptor density and of adenosine neuromodulation in the hippocampus of kindled rats. Eur J Neurosci 18:820-828

30. Turner CP, Pulciani D, Rivkees SA 2002 Reduction in intracellular calcium levels induces injury in developing neurons. Exp Neurol 178:21-32

31. Fredholm BB, Chen JF, Masino SA, Vaugeois JM 2005 Actions of adenosine at its receptors in the CNS: insights from knockouts and drugs. Annu Rev Pharmaco Toxicol 45:385-412

32. Rivkees SA 1995 The ontogeny of cardiac and neural A1 adenosine receptor expression in rats. Brain Res Dev Brain Res 89:202-213

33. Olanrewaju HA, Qin W, Feoktistov I, Scemama JL, Mustafa SJ 2000 Adenosine $\mathrm{A}(2 \mathrm{~A})$ and $\mathrm{A}(2 \mathrm{~B})$ receptors in cultured human and porcine coronary artery endothelial cells. Am J Physiol Heart Circ Physiol 279:H650-H656

34. Eckle T, Faigle M, Grenz A, Laucher S, Thompson LF, Eltzschig HK 2008 A2B adenosine receptor dampens hypoxia-induced vascular leak. Blood 111:2024-2035

35. Lu Q, Harrington EO, Newton J, Casserly B, Radin G, Warburton R, Zhou Y, Blackburn MR, Rounds S 2010 Adenosine protected against pulmonary edema through transporter- and receptor A2-mediated endothelial barrier enhancement. Am J Physiol Lung Cell Mol Physiol 298:L755-L767

36. Linden J 2006 New insights into the regulation of inflammation by adenosine. J Clin Invest 116:1835-1837

37. Sitkovsky M, Lukashev D 2005 Regulation of immune cells by local-tissue oxygen tension: HIF1 alpha and adenosine receptors. Nat Rev Immunol 5:712-721

38. Zaynagetdinov R, Ryzhov S, Goldstein AE, Yin H, Novitskiy SV, Goleniewska K, Polosukhin VV, Newcomb DC, Mitchell D, Morschl E, Zhou Y, Blackburn MR, Peebles RS Jr, Biaggioni I, Feoktistov I 2010 Attenuation of chronic pulmonary inflammation in A2B adenosine receptor knockout mice. Am J Respir Cell Mol Biol 42:564-571

39. Bazzichi L, Trincavelli L, Rossi A, De Feo F, Lucacchini A, Bombardieri S, Martini C 2005 A2B adenosine receptor activity is reduced in neutrophils from patients with systemic sclerosis. Arthritis Res Ther 7:R189-R195

40. Linden J 1994 Cloned adenosine A3 receptors: pharmacological properties, species differences and receptor functions. Trends Pharmacol Sci 15:298-306

41. Rivkees SA, Chen M, Kulkarni J, Browne J, Zhao Z 1999 Characterization of the murine A1 adenosine receptor promoter, potent regulation by GATA- 4 and $\mathrm{Nkx} 2.5$. J Biol Chem 274:14204-14209

42. Turner CP, Yan H, Schwartz M, Othman T, Rivkees SA 2002 A1 adenosine receptor activation induces ventriculomegaly and white matter loss. Neuroreport 13:11991204

43. Adén U, Leverin AL, Hagberg H, Fredholm BB 2001 Adenosine A(1) receptor agonism in the immature rat brain and heart. Eur J Pharmacol 426:185-192

44. Millar D, Schmidt B 2004 Controversies surrounding xanthine therapy. Semin Neonatol 9:239-244

45. Fredholm BB 1995 Astra Award Lecture. Adenosine, adenosine receptors and the actions of caffeine. Pharmacol Toxicol 76:93-101

46. Fredholm BB, Chen JF, Cunha RA, Svenningsson P, Vaugeois JM 2005 Adenosine and brain function. Int Rev Neurobiol 63:191-270

47. Johansson B, Halldner L, Dunwiddie TV, Masino SA, Poelchen W, Gimenez-Llort L, Escorihuela RM, Fernandez-Teruel A, Wiesenfeld-Hallin Z, Xu XJ, Hardemark A, Betsholtz C, Herlenius E, Fredholm BB 2001 Hyperalgesia, anxiety, and decreased hypoxic neuroprotection in mice lacking the adenosine A1 receptor. Proc Natl Acad Sci U S A 98:9407-9412

48. Coelho JE, Rebola N, Fragata I, Ribeiro JA, de Mendonca A, Cunha RA 2006 Hypoxia-induced desensitization and internalization of adenosine A1 receptors in the rat hippocampus. Neuroscience 138:1195-1203

49. Blackburn MR, Datta SK, Kellems RE 1998 Adenosine deaminase-deficient mice generated using a two-stage genetic engineering strategy exhibit a combined immunodeficiency. J Biol Chem 273:5093-5100

50. Turner CP, Seli M, Ment L, Stewart W, Yan H, Johansson B, Fredholm BB, Blackburn M, Rivkees SA 2003 A1 adenosine receptors mediate hypoxia-induced ventriculomegaly. Proc Natl Acad Sci U S A 100:11718-11722

51. Back SA, Rivkees SA 2004 Emerging concepts in periventricular white matter injury. Semin Perinatol 28:405-414

52. Ment LR, Schwartz M, Makuch RW, Stewart WB 1998 Association of chronic sublethal hypoxia with ventriculomegaly in the developing rat brain. Brain Res Dev Brain Res 111:197-203

53. Othman T, Yan H, Rivkees SA 2003 Oligodendrocytes express functional A1 adenosine receptors that stimulate cellular migration. Glia 44:166-172

54. Stevens B, Porta S, Haak LL, Gallo V, Fields RD 2002 Adenosine: a neuron-glial transmitter promoting myelination in the CNS in response to action potentials. Neuron 36:855-868

55. Akundi RS, Rivkees SA 2009 Hypoxia alters cell cycle regulatory protein expression and induces premature maturation of oligodendrocyte precursor cells. PLoS ONE 4:e4739
56. Fogal B, McClaskey C, Yan S, Yan H, Rivkees SA 2010 Diazoxide promotes oligodendrocyte precursor cell proliferation and myelination. PLoS ONE 5:e10906

57. Schmidt B, Roberts RS, Davis P, Doyle LW, Barrington KJ, Ohlsson A, Solimano A, Tin W 2006 Caffeine therapy for apnea of prematurity. N Engl J Med 354:21122121

58. Back SA, Craig A, Luo NL, Ren J, Akundi RS, Ribeiro I, Rivkees SA 2006 Protective effects of caffeine on chronic hypoxia-induced perinatal white matter injury. Ann Neurol 60:696-705

59. Thomson MA, Yoder BA, Winter VT, Giavedoni L, Chang LY, Coalson JJ 2006 Delayed extubation to nasal continuous positive airway pressure in the immature baboon model of bronchopulmonary dysplasia: lung clinical and pathological findings. Pediatrics 118:2038-2050

60. Schmidt B, Roberts RS, Davis P, Doyle LW, Barrington KJ, Ohlsson A, Solimano A, Tin W 2007 Long-term effects of caffeine therapy for apnea of prematurity. N Engl J Med 357:1893-1902

61. Davis PG, Schmidt B, Roberts RS, Doyle LW, Asztalos E, Haslam R, Sinha S, Tin W 2010 Caffeine for apnea of prematurity trial: benefits may vary in subgroups. J Pediatr 156:382-387

62. Fatemi A, Wilson MA, Johnston MV 2009 Hypoxic-ischemic encephalopathy in the term infant. Clin Perinatol 36:835-858 vii

63. Rice JE III, Vannucci RC, Brierley JB 1981 The influence of immaturity on hypoxic-ischemic brain damage in the rat. Ann Neurol 9:131-141

64. Bona E, Aden U, Gilland E, Fredholm BB, Hagberg H 1997 Neonatal cerebral hypoxia-ischemia: the effect of adenosine receptor antagonists. Neuropharmacology 36:1327-1338

65. Aden U 2010 Adenosine, Caffeine and Hypoxic Ischemia. Presented at 48th Nobel Symposium. Caffeine and Health, Stockholm

66. Von Lubitz DK, Lin RC, Melman N, Ji XD, Carter MF, Jacobson KA 1994 Chronic administration of selective adenosine A1 receptor agonist or antagonist in cerebral ischemia. Eur J Pharmacol 256:161-167

67. Boissard CG, Lindner MD, Gribkoff VK 1992 Hypoxia produces cell death in the rat hippocampus in the presence of an A1 adenosine receptor antagonist: an anatomical and behavioral study. Neuroscience 48:807-812

68. Linden J 2005 Adenosine in tissue protection and tissue regeneration. Mol Pharmacol 67:1385-1387

69. Zhou Y, Murthy JN, Zeng D, Belardinelli L, Blackburn MR 2010 Alterations in adenosine metabolism and signaling in patients with chronic obstructive pulmonary disease and idiopathic pulmonary fibrosis. PLoS ONE 5:e9224

70. Wendler CC, Poulsen RR, Ghatpande S, Greene RW, Rivkees SA 2010 Identification of the heart as the critical site of adenosine mediated embryo protection. BMC Dev Biol 10:57

71. Wendler CC, Amatya S, McClaskey C, Ghatpande S, Fredholm BB, Rivkees SA $2007 \mathrm{~A} 1$ adenosine receptors play an essential role in protecting the embryo against hypoxia. Proc Natl Acad Sci U S A 104:9697-9702

72. Browne ML 2006 Maternal exposure to caffeine and risk of congenital anomalies: a systematic review. Epidemiology 17:324-331

73. Christian MS, Brent RL 2001 Teratogen update: evaluation of the reproductive and developmental risks of caffeine. Teratology 64:51-78

74. Ross CP, Persaud TV 1986 Cardiovascular primordium of the rat embryo following in utero exposure to alcohol and caffeine. Can J Cardiol 2:160-163

75. Ross CP, Persaud TV 1986 Early embryonic development in the rat following in utero exposure to alcohol and caffeine. Histol Histopathol 1:13-17

76. Grosso LM, Triche EW, Belanger K, Benowitz NL, Holford TR, Bracken MB 2006 Caffeine metabolites in umbilical cord blood, cytochrome P-450 1A2 activity, and intrauterine growth restriction. Am J Epidemiol 163:1035-1041

77. Cnattingius S, Signorello LB, Anneren G, Clausson B, Ekbom A, Ljunger E, Blot WJ, McLaughlin JK, Petersson G, Rane A, Granath F 2000 Caffeine intake and the risk of first-trimester spontaneous abortion. N Engl J Med 343:1839-1845

78. Weng X, Odouli R, Li DK 2008 Maternal caffeine consumption during pregnancy and the risk of miscarriage: a prospective cohort study. Am J Obstet Gynecol 198:279.e1-279.e8

79. Vik T, Bakketeig LS, Trygg KU, Lund-Larsen K, Jacobsen G 2003 High caffeine consumption in the third trimester of pregnancy: gender-specific effects on fetal growth. Paediatr Perinat Epidemiol 17:324-331

80. Larroque B, Kaminski M, Lelong N, Subtil D, Dehaene P 1993 Effects of birth weight of alcohol and caffeine consumption during pregnancy. Am J Epidemiol 137:941-950

81. Wendler CC, Busovsky-McNeal M, Ghatpande S, Kalinowski A, Russell KS, Rivkees SA 2009 Embryonic caffeine exposure induces adverse effects in adulthood. FASEB J 23:1272-1278

82. Momoi N, Tinney JP, Liu LJ, Elshershari H, Hoffmann PJ, Ralphe JC, Keller BB, Tobita K 2008 Modest maternal caffeine exposure affects developing embryonic cardiovascular function and growth. Am J Physiol Heart Circ Physiol 294:H2248$\mathrm{H} 2256$ 